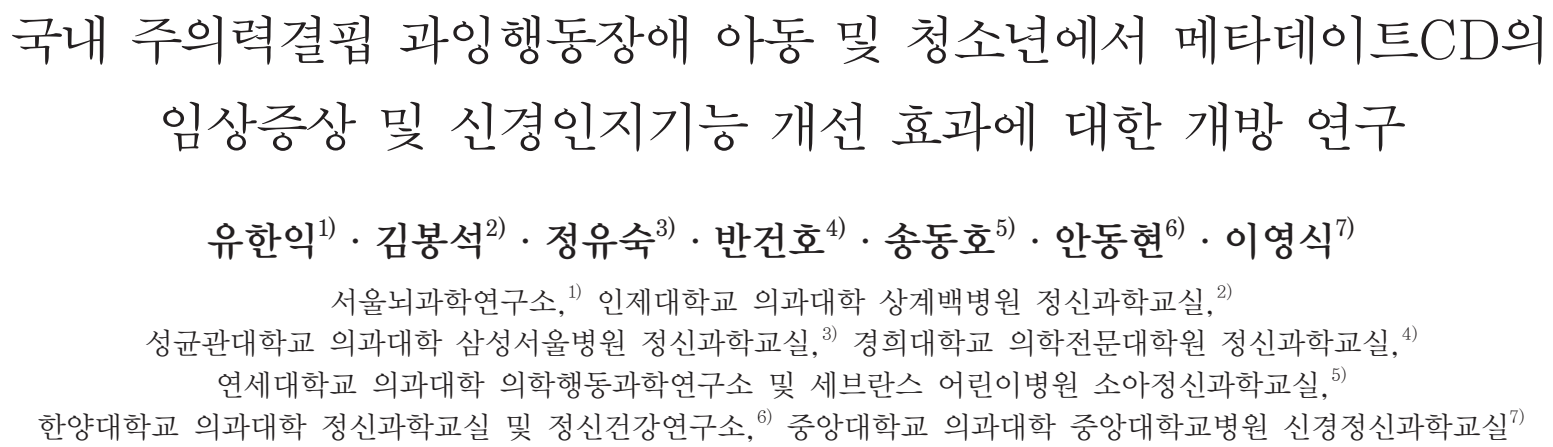

\title{
An Open-Label Study of the Improvements in Clinical Symptoms and Neurocognitive Functions in Korean Children and Adolescents with Attention- Deficit Hyperactivity Disorder after Treatment with Metadate CD
}

\author{
Hanik K. Yoo, M.D., Ph.D. ${ }^{1)}$, Bongseog Kim, M.D., Ph.D. ${ }^{2)}$, Yoo Sook Joung, M.D., Ph.D. ${ }^{3)}$, \\ Geon Ho Bahn, M.D., Ph.D. ${ }^{4)}$, Dong Ho Song, M.D., Ph.D. ${ }^{5}$, \\ Dong Hyun Ahn, M.D., Ph.D. ${ }^{6)}$ and Young Sik Lee, M.D., Ph.D. ${ }^{7)}$ \\ ${ }^{1)}$ Seoul Brain Research Institute, Seoul, Korea \\ ${ }^{2)}$ Department of Psychiatry, Sanggye Paik Hospital, College of Medicine, Inje University, Seoul, Korea \\ ${ }^{3)}$ Department of Psychiatry, Samsung Medical Center, Sungkyunkwan University School of Medicine, Seoul, Korea \\ ${ }^{4)}$ Department of Psychiatry, Kyung Hee University School of Medicine, Seoul, Korea \\ ${ }^{5)}$ Department of Child \& Adolescent Psychiatry, Severance Children's Hospital \\ and Institute for Behavioral Science in Medicine, Yonsei University College of Medicine, Seoul, Korea \\ ${ }^{6)}$ Department of Psychiatry and Institute of Mental Health, Hanyang University College of Medicine, Seoul, Korea \\ ${ }^{7)}$ Department of Neuropsychiatry, Chung-Ang University College of Medicine, Seoul, Korea
}

Objectives : This study aimed to investigate the efficacy and safety of Metadate CD (MCD) when given to Korean children and adolescents with attention-deficit hyperactivity disorder (ADHD). We also explored the effects of the drug on diverse neurocognitive functions.

Methods : Ninety-one subjects with ADHD (mean age 8.6 2.2 years) were recruited at 6 outpatient clinics in Seoul, Korea. We used the ADHD Rating Scale (ARS), Clinical Global Impression (CGI), and comprehensive attention test (CAT) to measure the drug's effects.

Results : After $0.92 \pm 0.32 \mathrm{mg} / \mathrm{kg} / \mathrm{day}$ of MCD were administered for $57.4 \pm 7.6$ days, there was a $48.5 \%$ reduction in the mean total ARS scores $(\mathrm{p}<.001)$. Fifty-seven subjects $(64.8 \%)$ showed either much improved or very much improved outcomes on the CGI-Improvement scale. The CGI-Severity scale also decreased from an average of 4.7 to an average of 2.9 ( $p<.001)$. Errors and response time standard deviations of the CAT, sustained attention test-to-response tasks, the flanker test, and divided attention test scores decreased after treatment $(\mathrm{p}<.05)$. The forward memory span of the spatial working memory test scores increased $(\mathrm{p}<.05)$. Thirty-five patients (39.8\%) experienced side effects, of which the most common were headache (14.8\%), nausea (12.5\%), and anorexia $(9.1 \%)$.

Conclusion : This open-label study suggests that MCD is effective and safe in improving the symptoms and neurocognitive functions of Korean children and adolescents with ADHD.

KEY WORDS : ADHD $\cdot$ Metadate CD $\cdot$ Effectiveness $\cdot$ Safety $\cdot$ Comprehensive Attention Test. 


\section{서 론}

주의력결핍 과잉행동장애(attention-deficit hyperactivity disorder, $\mathrm{ADHD}$ )는 아동기에 발생하는 가장 흔한 정신장애 중 하나이며, 중추신경자극제를 비롯한 약물치료를 통해 증 상 및 기능이 상당히 호전되는 것으로 알려져 있다.) 특히 약 물의 작용 시간을 늘린 서방형 제제는 약물 역동학적인 강점과 순응도의 증가 등으로 인해 사용량이 점차 늘어나고 있다. ${ }^{2.3}$ 하 지만 속효성 제제에 비해 효과가 시작되는 시점이 느리고, 부 작용이 오랫동안 발생할 가능성이 높은 단점이 있다. ${ }^{45}$

메타데이트 $\mathrm{CD}$ (Metadate Controlled Delivery, $\mathrm{MCD}$ )는 서 방형 메칠페니데이트(methylphenidate, MPH) 제제로서 속방 형과 지속형이 일정 비율로 섞여 있는 약물이다. 이 약물은 이 미 외국에서 대조군 비교 연구에서 효과와 안전성이 입증되었 고, 속방형 $\mathrm{MPH}$ 와의 교차 연구를 통해서도 효과가 동등하다 는 것이 밝혀졌다. ${ }^{6}$ Dirksen 등ㄱㅇㅢ 연구에 의하면 ADHD 308 명의 대상자 중에서 $65 \%$ 가 치료에 반응을 보였다.

주의력 및 실행기능과 같은 신경인지기능의 저하는 $\mathrm{ADHD}$ 의 핵심 병리로서 환자의 증상 및 기능 저하와도 밀접하게 연 관되어 있다. ${ }^{8)}$ 또한 현재까지의 여러 연구를 통해 $\mathrm{ADHD}$ 의 증상 개선에 효과가 있는 약물에 의해 신경인지기능도 상당히 변화되는 것으로 알려져 있다. 하지만 증상 개선에 비해서는 효과의 크기가 작을 뿐만 아니라 결과도 일관성이 부족하여 아직까지 특정한 결론을 이끌어내기 어렵다. ${ }^{8)}$

$\mathrm{MPH}$ 에 의한 신경인지기능의 호전 여부를 조사한 최근의 국내 연구결과를 보면, 약물치료 후에 지속수행검사의 일부 소검사 점수가 유의하게 변화되었다. ${ }^{9-13)}$ 하지만 한 연구를 제 외하고는 모두 지속수행검사만을 사용한 연구였기 때문에, 단 순 지속주의력이나 경계력, 인지적 충동성을 제외한 보다 포 괄적인 신경인지기능에 미치는 약물의 영향에 대한 자료는 보고되지 않았다.

더욱이 $\mathrm{MCD}$ 의 효과와 안전성을 국내 아동 및 청소년에서 조사한 연구는 현재까지 없었다. 따라서 본 연구는 국내 ADHD 아동 및 청소년에서 $\mathrm{MCD}$ 의 효과와 부작용, 그리고 지속수 행능력, 억제능력, 일부 실행기능, 비언어적 작업기억력과 같은 포괄적인 신경인지기능에 미치는 약물의 효과를 조사하기 위 해 실시되었다.

\section{방 법}

\section{1. 대 상}

주의력결핍 및 과잉운동성, 충동성을 주증상으로 종합병
원 소아청소년정신과 외래를 방문한 아동 및 청소년을 대상 으로 실시되었다. 서울시내에 있는 총 6개 병원이 연구에 참 여하였으며, 2008년 12월부터 2009년 10월까지 대상자를 모 집하였다. $\mathrm{ADHD}$ 진단은 $\mathrm{DSM}-\mathrm{IV}$ 진단 기준을 따랐으며 정 신과 전문의에 의해 한국판 Kiddie-Schedule for Affective Disorders and Schizophrenia-Present and Lifetime Ver$\operatorname{sion}(\mathrm{K}-\mathrm{SADS}-\mathrm{PL})^{14)}$ 을 사용하여 진단하였다. 이외에도 향정 신성 약물 투여 경험이 없는 경우 또는 약물을 복용하였더라 도 6 개월 이내 향정신성 약물 치료가 1 개월 미만이었던 경우, 피험자 및 부모(또는 법적 대리인)가 적절하게 의사 소통할 수 있을 정도의 충분한 이해력이 있는 경우에만 연구에 참여시 켰다. 하지만 $\mathrm{ADHD}$ 보다 우선하는 정신과적 질환이 동반된 경 우, 전반적 발달장애가 있는 경우, 지능지수가 70점 이하인 경 우, 현재 연구에 참여하기 어려울 정도의 신경과 또는 내과적 질 환이 있는 경우, 녹내장, 갑상선기능항진증이 있는 경우, $\mathrm{MPH}$ 에 과민반응을 가진 경우, 실험실 검사 결과 심각한 간기능 및 신장기능의 저하가 의심되는 경우는 제외하였다.

\section{2. 평가도구}

\section{1) 한국판 $\mathrm{ADHD}$ 평정척도(ARS)}

환자의 $\mathrm{ADHD}$ 증상의 심각도를 평가하기 위해서 $\mathrm{ARS}$ 를 사용하였다. 이는 연구자가 직접 평가하는 36 문항의 평가 도구 로서 총점, 주의력결핍 점수, 과잉운동성/충동성 점수로 평 가된다. ${ }^{15)}$

\section{2) Clinical Global Impression(CGI)}

임상적인 기능 수준을 평가하기 위해서 Clinical Global Impression-Improvement scale(CGI-I $)^{16}$ 와 CGI-Severity of Illness scale $(\mathrm{CGI}-\mathrm{S})^{17)}$ 을 사용하였다. CGI는 1점에서 7점까 지 평가되며, CGI-I는 1=very much improved, 2=much improved, $3=$ minimally improved, $4=$ no change, $5=$ minimally aggravated, $6=$ much aggravated, $7=$ very much aggravated 로 나눠져 있으며, CGI-S는 1=not ill, 2=very mild, 3=mild, 4= moderate, $5=$ marked, $6=$ severe, $7=$ very severe로 나눠져 있다.

$\mathrm{ARS}$ 와 $\mathrm{CGI}$ 는 약물치료 전, 약물 투여 후 2주, 4주, 그리 고 마지막 방문시 연구자가 직접 평가하였다.

3) 종합주의력검사 도구(Comprehensive Attention Test, CAT)

연구참여자의 신경인지기능 평가를 위해서 CAT를 사용하 였다. 이 검사는 전산화 검사로서 이미 국내에 신뢰도 조사 및 표준화 연구 ${ }^{18}$ 가 실시되었고, 임상적으로 폭넓게 사용 중인 검 사 도구이다. 약물 투여 전과 마지막 방문시에 평가되었다. CAT를 통해 평가할 수 있는 인지기능은 아래와 같다. 
(1) 단순선택주의력-시각(Visual selective attention task) 원하는 시각자극에 반응할 수 있는 능력을 측정하는 검사 다. 여러 개의 시각적 자극을 보고 특정자극을 찾아내도록 하 는 검사로서, 화면에 2초 간격으로 다양한 도형들이 제시되 면, 원모양이 나올 때마다 버튼을 최대한 빨리 누르도록 한다.

(2) 단순선택주의력-청각(Auditory selective attention task) 원하는 청각 반응에 반응할 수 있는 능력을 측정하는 검 사로서, 2 초 간격으로 다양한 소리가 제시될 때, 종소리가 들 릴 때마다 버튼을 최대한 빨리 누르도록 한다.

(3) 억제지속주의력(Sustained attention to response task) 지속적으로 주의력을 유지하며 충동성을 억제하는 능력을 측정하는 검사다. 하나의 특정자극을 제외한 모든 자극들에 일관된 반응을 보임으로써, 특정자극에 대한 억제가 유지되 는지를 평가한다. 도형들이 나올 때마다 스페이스 바를 최대 한 빨리 누르다가 엑스 $(\mathrm{X})$ 자 모양이 제시되는 경우에는 누르 지 않도록 한다.

(4) 간섭선택주의력(Flanker task)

주위의 간섭자극을 무시하고 필요한 자극에 반응할 수 있 는 능력을 측정하는 검사다. 여러 개의 시각자극을 한꺼번에 보여주고, 그 중에서 특정자극의 특징에 따라 반응하는 능력 을 평가한다. 화면에 한 면이 열려있는 다섯 개의 상자가 주어 지면, 가운데 상자의 열린 면의 방향과 일치하는 방향키를 최대한 빨리 누르도록 한다.

(5) 분할주의력(Divided attention task)

두 가지 자극을 동시에 처리할 수 있는 능력을 측정하는 검 사다. 시각과 청각자극을 동시에 연속적으로 제시하고 이를 처리하는, 높은 수준의 주의력을 평가한다. 화면에 소리와 그 림이 동시에 제시되면, 바로 앞서 제시된 자극의 소리가 반복 되거나 도형이 반복되는 경우에 스페이스 바를 최대한 빨리 누르도록 되어 있다.

(6) 공간작업기억력(Spatial working memory task)

일련의 자극들을 순서대로 기억하며 처리하는 능력을 측정 한다. 시각자극을 바로 또는 거꾸 정확하게 기억하는 정도를 평가하는 검사로서 화면에 표시된 박스들의 색이 순서대로 바뀌면, 그 순서를 기억하고 있다가 마우스를 이용하여 박스 가 나온 순서대로 또는 역순으로 박스를 클릭한다.

안전성에 대한 평가는 매 방문마다 연구자에 의해 이루어 졌다. 시험기간 중 나타난 이상반응에 대해 조사하였고, 약물 복용 전 및 마지막 방문시 실험실 검사, 생체징후, 이학적검사, 체중 및 신장 평가를 실시하였다. 실험실 검사에는 일반혈액
검사, 일반화학검사, 심전도, 가임여성의 경우 소변임신검사가 포함되었다.

\section{3. 과 정}

본 연구는 4상, 다기관, 개방형 시험으로 설계되었다. 연구 프로토콜은 6개 참여센터의 연구윤리위원회의 심의를 거쳤 다. 피험자의 동의서와 수락서를 서면으로 획득한 후에 연구 과정이 시작되었다. 적합성 평가, 인구학적 조사, 병력조사, 이 학적검사, 체중 및 신장 측정, 생체징후 측정하였다. 상기 평가 결과 연구참여자로 합당한 경우에 연구자용 ARS와 CGI 및 CAT 평가를 실시하였다.

약물 투여는 피험자의 체중이 $20 \mathrm{~kg}$ 미만인 경우에는 하루에 $10 \mathrm{mg}$ 으로 약물 복용을 시작하고, $20 \mathrm{~kg}$ 이상이면 $20 \mathrm{mg}$ 으로 시 작하였다. 이후 연구자의 임상적 판단에 따라 최소 $10 \mathrm{mg} / \mathrm{day}$ 부 터 최대 $60 \mathrm{mg} / \mathrm{day}$ 까지 방문마다 용량을 변경시켰다. CGI-I 가 3점 이상이고 부작용이 견딜 수 있는 경우에 증량하였으며, 부작용이 견딜 수 없는 경우는 감량하였다. 약물 투여 후 2주, 4 주, 마지막으로 8 주 후에 병원을 방문하였다. 복약 순응도는 매 방문마다 캡슐의 수를 세어 확인하였으며, 순응도 $80 \%$ 미 만일 경우 연구에서 탈락되었다.

\section{4. 통계분석}

약물치료 전, 치료 2주 후, 4 주 후, 종결시점의 ARS, CGI$\mathrm{S}$, 체중 결과를 repeat measure of ANOVA를 이용해 분석하 였다. 사후검증으로는 Turkey test를 이용하였다. 약물치료 전 후의 CAT 결과는 paired t-test를 이용해 분석하였다. 최소한 1 회의 약물 투여 후 평가를 실시한 환자의 자료는 intent-totreatment 대상군으로 포함시켰으며, 누락자료는 last-observation-carried-forward 방식을 사용하여 처리하였다. 모든 자 료는 Statistica 7.0을 사용하여 분석하였고, 통계적 유의수준 은 $\alpha$ 값 $<0.05$ 로 하였다.

\section{결 과}

\section{1. 인구학적, 임상적 특성}

총 97 명 $(8.7 \pm 2.2$ 세)의 아동 및 청소년이 연구에 참여하였으

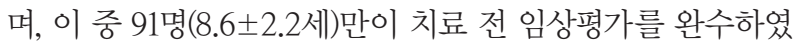
다. 이 중 3 명은 약물치료가 시작된 직후 첫 번째 평가 방문을 하지 않아 연구에서 탈퇴되었고, 결국 88명의 자료가 약물 전 후 분석에 사용되었다. 약물치료 후 1 회 평가 후에도 11 명의 환자가 추가로 탈락되어, 결국 77명이 끝까지 연구를 완수하 였다. 4명은 ‘약물 효과 부족, 3명은 '순응도 문제', 3명은 ‘부 작용', 1 명은 '증상의 현저한 호전'으로 인해 조기 탈락하였다. 91명의 환자군 중 남자가 77명(84.6\%)이었고, 혼합형이 62 
명(68.1\%), 부주의성 우세형이 27명(29.7\%), 과잉운동/충동성 우세형이 2명(2.2\%)이었다. 또한 9명(9.9\%)에서 과거 $\mathrm{ADHD}$ 치료제를 복용한 경험이 있었다. $\mathrm{MCD}$ 를 처방받은 기간은 평 균 57.4 일이었고, 용량은 하루 평균 $31 \mathrm{mg}(0.92 \mathrm{mg} / \mathrm{kg})$ 이었다 (Table 1).

\section{2. 약물 효과}

\section{1) ARS 및 CGI 결과}

8주간의 $\mathrm{MCD}$ 의 치료 후 연구자가 평가한 $\mathrm{ARS}$ 총점은 33.2 점에서 17.1점으로 $48.5 \%$ 가 감소하였다 $(\mathrm{t}=184.1, \mathrm{p}<.001)$. 약 물 투여 2주 후에는 19.2\%(p<.001), 4주 후에는 36.7\%(p< .001) 감소하여 점수가 점차 감소되는 경향을 보였다. 주의력 결핍 점수는 치료 전 19.0점에서 8주 치료 후 9.9점으로 $47.9 \%$ $(\mathrm{F}=204.5, \mathrm{p}<.001)$ 호전되었으며, 약물치료 2주 및 4주 후에 도 각각 $19.5 \%(\mathrm{p}<.001), 36.8 \%(\mathrm{p}<.001)$ 감소하였다. 과잉행 동/충동성 점수는 치료 전 14.3점에서 8주 치료 후 7.2점으로 49.7\%(F=99.2, $\mathrm{p}<.001)$ 호전되었으며, 치료 2주 및 4주 후에 각각 $18.9 \%(\mathrm{p}<.001), 37.1 \%(\mathrm{p}<.001)$ 호전되는 소견을 보였 다(Table 2).

CGI-S는 치료 전 4.7점에서 치료 종결 후 2.9점(F=102.1, $\mathrm{p}<.001$ )으로 감소되었으며, 역시 치료 2주 및 4주 후에 각각

Table 1. Descriptive data about subjects and medication

\begin{tabular}{lc}
\hline Gender & $77(84.6 \%)$ \\
Male & $14(15.4 \%)$ \\
Female & $8.6 \pm 2.2$ years \\
Age & $(6$ to 14 years $)$ \\
ADHD subtypes & $27(29.7 \%)$ \\
Predominantly inattentive & $2(2.2 \%)$ \\
Predominantly hyperactive/impulsive & $62(68.1 \%)$ \\
Combined & \\
Concurrent comorbidities & 2 \\
Tic disorders & 1 \\
Enuresis & 1 \\
Communication disorder & 1 \\
Trichotillomania & \\
Previous drug history & \\
Methylphenidate immediate & \\
releasing form & \\
Methylphenidate sustained & \\
releasing form & \\
Atomoxetine & \\
Unidentified drugs & \\
Dose of Metadate CD & 1 \\
& \\
Duration of Metadate CD & \\
medication & $(10$ to $60 \mathrm{mg} / \mathrm{day})$ \\
\hline
\end{tabular}

4.1점 $(\mathrm{p}<.001), 3.4$ 점 $(\mathrm{p}<.001)$ 으로 지속적인 감소 추세를 보였 다(Table 2). 치료 종결 시점의 CGI-I가 'very much improved,' 와 'much improved'인 환자는 57명으로 전체 중 64.8\%가 반 응군으로 나타났다(Table 2).

치료 시작 2주, 4 주, 8 주 후 $\mathrm{MCD}$ 의 평균 용량은 각각 17.1 $\pm 6.4 \mathrm{mg}, 26.0 \pm 9.1 \mathrm{mg}, 30.1 \pm 11.4 \mathrm{mg}$ 이었다.

\section{2) CAT 결과}

8주 동안의 약물치료 후 CAT 점수의 변화를 Table 3에 기 술하였다. 치료 전후로 시각선택주의력의 오경보오류 $(\mathrm{t}=4.3$, $\mathrm{p}<.001)$, 반응시간의 표준편차 $(\mathrm{t}=3.3, \mathrm{p}<.01)$ 가 유의하게 감 소하였다. 청각선택주의력의 경우에는 누락오류 $(\mathrm{t}=2.6, \mathrm{p}<$ $.05)$, 오경보오류 $(\mathrm{t}=2.2, \mathrm{p}<.05)$, 반응시간 평균 $(\mathrm{t}=2.5, \mathrm{p}<.05)$, 반응시간의 표준편차 $(\mathrm{t}=3.7, \mathrm{p}<.001)$ 가 감소하였다. 억제지속 주의력 및 간섭선택주의력의 누락 $(\mathrm{t}=3.2, \mathrm{p}<.01 ; \mathrm{t}=2.8, \mathrm{p}<$ .05) 및 오경보오류 $(\mathrm{t}=7.1, \mathrm{p}<.001 ; \mathrm{t}=4.4, \mathrm{p}<.001)$, 반응시간 표 준편차 $(\mathrm{t}=4.6, \mathrm{p}<.001 ; \mathrm{t}=4.3, \mathrm{p}<.001)$ 가 약물치료에 의해 각 각 감소하였다. 분할주의력은 누락오류 $(\mathrm{t}=4.0, \mathrm{p}<.001)$ 와 반응 시간 표준편차 $(\mathrm{t}=2.6, \mathrm{p}<.05)$ 가 감소하였고, 공간작업기억력은 치료 후 전방향 기억폭 $(\mathrm{t}=-4.0, \mathrm{p}<.05)$ 의 증가가 관찰되었다 (Table 3).

\section{3) 부작용}

부작용 분석에 포함된 88명의 환자 중 35명(39.8\%)에서 연 구 기간 중 한 번 이상의 부작용이 보고되었다(Table 4). 하지만 이 중에서 부작용으로 인해 조기 탈락된 환자는 3명(3.4\%)이 었다. 가장 흔한 부작용은 두통으로서 $14.8 \%$ 에서 경험하였고, 오심(12.5\%), 식욕저하(9.1\%), 복통(5.7\%), 불면(4.5\%)이 다음으 로 흔하게 보고되었다(Table 4). 하지만 대부분의 부작용은 경미한 수준이었으며, 부작용을 경험한 환자 중 결국 약물을 영구적으로 중단한 사례는 1 명에 불과했다.

약물의 부작용을 조사하기 위해 실시한 일반혈액검사, 일반 화학검사 결과 임상적으로 의미있는 변화가 관찰되지 않았다. 심전도검사에서도 특이 사항이 발견되지 않았다. 활력 증후도 약물 치료 전후로 의미있는 변화가 나타나지 않았다. 체중은 치 료 전 평균 $35.1 \mathrm{~kg}$ 에서 8 주 치료 후 $34.8 \mathrm{~kg}$ 로 $0.3 \mathrm{~kg}$ 감소하였지 만 통계적 유의성은 없었다. 사후 검증 결과 약물치료 전과 치 료 4주 후에 평가한 체중만이 유의하게 감소하였다 $(\mathrm{p}=.03)$.

\section{고 찰}

본 연구는 국내 $\mathrm{ADHD}$ 아동 및 청소년을 대상으로 $\mathrm{MPH}$ 서방형 제제 중 하나인 $\mathrm{MCD}$ 의 단기간 효과 및 안전성, 그리 고 신경인지기능 검사의 변화를 조사한 첫 연구다. 본 연구 
Table 2. Efficacy of metadate CD

\begin{tabular}{|c|c|c|c|c|}
\hline Characteristics & Baseline & 2 weeks & 4 weeks & Endpoint \\
\hline \multicolumn{5}{|c|}{ ADHD rating scale (mean \pm SD) } \\
\hline Inattentive & $19.0 \pm 4.2$ & $15.3 \pm 4.5^{*}$ & $12.0 \pm 4.9^{*}$ & $9.9 \pm 4.8^{*}$ \\
\hline Hyperactive/Impulsive & $14.3 \pm 5.0$ & $11.6 \pm 5.3^{*}$ & $9.0 \pm 4.7^{*}$ & $7.2 \pm 4.3^{*}$ \\
\hline Total & $33.2 \pm 6.8$ & $26.8 \pm 8.3^{*}$ & $21.0 \pm 8.7^{*}$ & $17.1 \pm 8.1^{*}$ \\
\hline \multicolumn{5}{|l|}{ CGI-I, n (\%) } \\
\hline Very much improved & - & $1(1.1)$ & $8(9.1)$ & $22(25.0)$ \\
\hline Much improved & - & $18(20.5)$ & $40(45.5)$ & $35(39.8)$ \\
\hline Minimally improved & - & $46(52.3)$ & $34(38.6)$ & $25(28.4)$ \\
\hline No change & - & $20(22.7)$ & $6(6.8)$ & $5(5.7)$ \\
\hline Minimally aggravated & - & $3(3.4)$ & 0 & 0 \\
\hline Much aggravated & - & 0 & 0 & $1(1.1)$ \\
\hline Very much aggravated & - & 0 & 0 & 0 \\
\hline CGI-S (mean \pm SD) & $4.7 \pm 0.8$ & $4.1 \pm 1.0^{*}$ & $3.4 \pm 1.0^{*}$ & $2.9 \pm 1.0^{*}$ \\
\hline \multicolumn{5}{|l|}{ CGI-S, n (\%) } \\
\hline Normal, not ill & 0 & 0 & $3(3.4)$ & $9(10.2)$ \\
\hline Minimally ill & 0 & $3(3.4)$ & $11(12.5)$ & $23(26.1)$ \\
\hline Mildly ill & $7(8.0)$ & $25(25.0)$ & $33(37.5)$ & $30(34.1)$ \\
\hline Moderately ill & $28(31.8)$ & $35(39.8)$ & $29(33.0)$ & $23(26.1)$ \\
\hline Markedly ill & $41(46.6)$ & $24(27.3)$ & $10(11.4)$ & $3(3.4)$ \\
\hline Severely ill & $11(12.5)$ & $3(3.4)$ & $2(2.3)$ & 0 \\
\hline Extremely severely ill & $1(1.1)$ & $1(1.1)$ & 0 & 0 \\
\hline
\end{tabular}

Regarding to the dropout cases, the Last Observation Carried Forward method was applied. $*: \mathrm{p}<.001$, significant changes between baseline and post-treatment. ADHD : attention-deficit hyperactive disorder, CGI-I : Clinical Global Impression-Improvement scale, CGI-S : Clinical Global Impression-Severity of Illness scale

결과, $\mathrm{MCD}$ 치료를 통해 $\mathrm{ADHD}$ 의 증상 및 기능이 의미있게 호전되었으며, 더불어 신경인지기능이 향상되었다. 부작용면 에서도 비교적 안전한 것으로 나타났다. 이는 $\mathrm{MCD}$ 의 주의력 개선 효능 및 안전성을 조사한 과거 외국의 연구결과와 일치 하는 소견이며, ${ }^{6,7)}$ 국내 ADHD 환자를 대상으로 실시되었던 다른 서방형 MPH 제형의 연구와도 유사한 결과다.,13,19,20) 이 는 $\mathrm{MCD}$ 가 다른 $\mathrm{MPH}$ 제형처럼 국내에서도 $\mathrm{ADHD}$ 의 1차 치료제로 사용되는 것이 합당함을 시사하는 소견이다. ${ }^{21}$

$\mathrm{MCD}$ 는 $70 \%$ 의 서방형 $\mathrm{MPH}$ 와 $30 \%$ 의 속효성 $\mathrm{MPH}$ 가 혼 합되어 있으며, 이로 인해 안정적인 약역학적 분포를 갖고 있 다. 평균 반감기가 5.6 6.8시간으로 일반적으로 국내에서 사용 되고 있는 속효성 $\mathrm{MPH}$ 보다는 길고 Concerta ${ }^{\circledR}$ 보다는 짧다. ${ }^{22)}$ 이런 특성으로 인해 같은 $\mathrm{MPH}$ 제형이라 하더라도 효과와 부작용 측면에서 차이가 있으며, 이런 차이점은 임상상황에 서 정신자극제 선택에 영향을 미치는 요소로 작용한다. 예를 들어, $\mathrm{MCD}$ 의 반감기는 한 번의 투약으로 학교 생활에 미치 는 $\mathrm{ADHD}$ 부정적인 측면을 감소시키는 데 충분하다고 보고 되었다. ${ }^{6}$ 속효성 $\mathrm{MPH}$ 에 비해 식사시간에 영향을 받지 않는 안정된 약역학적 분포 ${ }^{23}$ 와 하루 1 회 투약의 편리함으로 인해 $71 \%$ 의 부모로부터 속효성 $\mathrm{MPH}$ 를 사용할 때보다 더 만족스 럽다는 평가를 받았다.7) Concerta ${ }^{\circledR}$ 보다 작용시간은 짧지만
오전 시간에 더 높은 혈중농도를 보이기 때문에, 오전에는 $\mathrm{MCD}$ 가 더 효과적이고 오후에는 두 약물이 동일하며 이른 저녁시 간에는 Concerta ${ }^{\circledR}$ 가 더 효과적이라는 보고도 있다. ${ }^{24}$ 작용시 간이 길면 부작용도 더 오래 나타나기 때문에, 특히 부작용이 심한 환자에게는 작용시간이 짧은 $\mathrm{MCD}$ 가 선택되는 경향이 있다. 또한 나이가 어려서 제형을 그대로 삼키기 어려운 환자 들에게는 캡슐을 열어 sprinkle 형태로 복용해도 동일한 효 과를 기대할 수 있다. ${ }^{25}$ 이런 정보들은 $\mathrm{ADHD}$ 아동 및 청소년에 게 $\mathrm{MCD}$ 를 처방하는 임상의들에게 매우 유용하게 활용된다.

저자들이 조사한 바로는 국내는 물론 외국에서도 $\mathrm{MCD}$ 를 사용하여 신경인지기능의 변화를 조사한 연구는 거의 없었다. $\mathrm{MPH}$ 의 인지기능에 미치는 영향에 대한 연구결과들은 많이 보고되었으나, 단순한 형태의 지속수행검사를 사용한 것이 많 았고, 결과 또한 다양하였다. ${ }^{8,26}$ 전체적으로 보면 약물치료 전 후 효과크기는 평균 0.56 이며, $75 \%$ 에서 오류 수가 감소하고, $65 \%$ 에서 반응시간이 감소한다. ${ }^{26)}$ 이처럼 지속수행검사는 $\mathrm{ADHD}$ 의 진단 도구로는 유용성이 증명되지 않았지만, ${ }^{27,28)}$ 약물 전 후의 효과를 판정하기 위해서는 비교적 유용하게 사용될 수 있다. ${ }^{26)}$ 또한 치료 전 지속수행검사의 반응속도의 표준편차가 높을수록 약물 반응이 좋지 않다는 연구결과'가 있는데, 예 비적이기는 하지만 약물 반응의 예측인자로 사용될 가능성 
메타데이트 $\mathrm{CD}$ 의 증상 및 신경인지기능 개선 효과

Table 3. Mean and standard deviation of the Comprehensive Attention Test between baseline and endpoint

\begin{tabular}{|c|c|c|c|c|c|}
\hline \multirow{2}{*}{ Subtests } & & \multicolumn{2}{|c|}{ Baseline } & \multicolumn{2}{|c|}{ Endpoint } \\
\hline & & Mean & SD & Mean & SD \\
\hline \multirow[t]{4}{*}{ Visual selective attention test } & OE & 5.14 & 7.94 & 3.80 & 8.44 \\
\hline & $C E^{*}$ & 11.10 & 10.80 & 6.54 & 10.03 \\
\hline & RT (ms) & 564.36 & 137.19 & 548.27 & 134.32 \\
\hline & RT SD $(\mathrm{ms})^{\dagger}$ & 209.52 & 106.62 & 176.55 & 83.58 \\
\hline \multirow[t]{4}{*}{ Auditory selective attention test } & $\mathrm{OE}^{+}$ & 4.51 & 9.69 & 1.80 & 4.20 \\
\hline & $\mathrm{CE}^{+}$ & 6.40 & 288.78 & 4.23 & 6.08 \\
\hline & $\mathrm{RT}(\mathrm{ms})^{\phi}$ & 657.70 & 161.90 & 613.94 & 146.98 \\
\hline & RT SD $(\mathrm{ms}) *$ & 228.24 & 122.05 & 181.94 & 80.55 \\
\hline \multirow[t]{4}{*}{ Sustained attention test to response task } & $\mathrm{OE}^{\dagger}$ & 17.41 & 22.87 & 10.24 & 17.13 \\
\hline & $C E^{*}$ & 27.35 & 15.47 & 16.75 & 13.58 \\
\hline & $\mathrm{RT}(\mathrm{ms})$ & 549.26 & 119.37 & 552.19 & 139.33 \\
\hline & $\mathrm{RT} \mathrm{SD}(\mathrm{ms})^{*}$ & 228.68 & 108.63 & 184.66 & 80.15 \\
\hline \multirow[t]{4}{*}{ Flanker test } & $\mathrm{OE}^{\dagger}$ & 15.68 & 24.32 & 8.00 & 12.28 \\
\hline & CE* & 23.38 & 19.05 & 14.88 & 16.52 \\
\hline & $\mathrm{RT}(\mathrm{ms})$ & 628.78 & 177.85 & 600.85 & 159.36 \\
\hline & RT SD $(\mathrm{ms}) *$ & 246.20 & 151.18 & 174.25 & 95.34 \\
\hline \multirow[t]{4}{*}{ Divided attention test } & OE* & 12.64 & 8.87 & 8.03 & 8.01 \\
\hline & CE & 14.45 & 11.87 & 11.90 & 12.25 \\
\hline & $\mathrm{RT}(\mathrm{ms})$ & 738.89 & 220.25 & 718.36 & 135.84 \\
\hline & RT SD $(\mathrm{ms})^{\dagger}$ & 305.51 & 116.55 & 247.46 & 89.77 \\
\hline \multirow[t]{4}{*}{ Spatial working memory test } & $\mathrm{FMS}^{+}$ & 6.56 & 1.13 & 7.25 & 1.67 \\
\hline & FCR & 4.89 & 0.33 & 5.38 & 0.74 \\
\hline & BMS & 6.78 & 1.92 & 4.63 & 3.20 \\
\hline & $B C R$ & 4.89 & 0.93 & 3.63 & 2.26 \\
\hline
\end{tabular}

$*: \mathrm{p}<.001, \dagger: \mathrm{p}<.01, \ddagger: \mathrm{p}<.05 . \mathrm{SD}:$ standard deviation, OE : omission error, CE : commission error, RT : mean of the response times, ms : millisecond, RT SD : standard deviation of the response times, FMS : forward memory span, FCR : forward correct response, BMS : backward memory span, BCR : backward correct response

Table 4. Adverse events

\begin{tabular}{lcc}
\hline Adverse events & $\mathrm{n}$ & $\%(\mathrm{n}=88)$ \\
\hline Headache & 13 & 14.8 \\
Nausea & 11 & 12.5 \\
Anorexia & 8 & 9.1 \\
Stomachache & 5 & 5.7 \\
Insomnia & 4 & 4.5 \\
Cough & 3 & 3.4 \\
Fever & 1 & 1.1 \\
Diarrhea & 1 & 1.1 \\
Memory impairment & 1 & 1.1 \\
Irritability & 1 & 1.1 \\
Depression & 1 & 1.1 \\
Myalgia & 1 & 1.1 \\
Anxiety & 1 & 1.1 \\
Rhinorrhea & 1 & 1.1 \\
Trauma & 1 & 1.1 \\
Gastric discomfort & 1 & 1.1 \\
Hypersomnia & 1 & 1.1 \\
Neurological symptom & 1 & 1.1 \\
Itching & 1 & 1.1 \\
\hline
\end{tabular}

도 있다. 이 결과는 추후 추가적인 연구 자료가 더 필요하다.

이제까지 MPH의 인지기능 개선 효과에 대해 조사한 대부 분의 국내 연구 역시 지속수행검사가 주로 사용되었다. ${ }^{9-12)}$ 지 속수행검사 중에서도 시각 및 청각자극 중 목표자극에만 가 능한 빨리 반응하게 하여 정반응, 누락 및 오반응오류, 반응 속도 및 반응속도의 표준편차를 산출하는 가장 단순한 형태 가 대부분이었다. 이 검사는 $\mathrm{CPT} 1$ 혹은 $\mathrm{CPT}-\mathrm{X}$ 라고도 불리는 데, 목표자극의 빈도에 따라 경계력 혹은 지속주의력을 평가 할 수 있으며, 충동성도 평가할 수 있는 것으로 알려져 있다. ${ }^{26)}$ 본 연구의 시각 및 청각 단순선택주의력검사가 바로 $\mathrm{CPT} 1$ 에 해당된다. 본 연구결과 역시 국내외 연구결과와 마찬가지로 약물치료 후 오경보오류의 감소, 반응속도 표준편차의 감소 가 나타났다. 이는 $\mathrm{MPH}$ 가 $\mathrm{ADHD}$ 의 신경심리적 특성인 지속 주의력과 충동성을 효과적으로 줄여주고 있음을 시사하는 소견이다. ${ }^{8,26)}$

본 연구에서는 기존 국내 연구와는 달리 지속수행검사 중 목표자극의 빈도를 높여 얼마나 정확하고 빠르게 목표자극 에 반응하는지를 보는 동시에 비목표자극에 효과적으로 억 
제하는 능력을 평가하는 억제지속주의력을 평가하였다. 이 검사는 CPT-not X, Conners CPT 또는 CPT2라고도 불리며, $\mathrm{CPT} 1$ 에 비해 오경보오류의 가능성을 높임으로써 $\mathrm{ADHD}$ 에 서 흔히 보이는 억제 능력의 결손 정도를 더 잘 평가할 수 있 는 것으로 알려져 있다. ${ }^{26,27)}$ 본 연구결과에서도 치료 전 오경 보오류가 단순선택주의력검사에 비해 더 많았으며, 약물치 료 후 현저히 감소한 것으로 나타났다. 이는 억제능력을 평가 하는 stop/signal 과제 혹은 go/nogo 과제를 이용하여 약물 전후에 오경보오류 및 반응속도의 감소를 보고한 기존의 외 국 연구 결과와 일치하는 소견이다. ${ }^{29-33)}$

또한 본 연구에서는 두 가지 자극, 즉 청각과 시각 자극을 동시에 처리하는 분할주의력을 평가하였다. 본 연구에서 사 용한 분할주의력검사는 두 가지 자극을 동시에 처리하면서 동시에 바로 직전의 자극과 동일한 목표자극을 선택해서 반 응하는 CPT-IP(Identical Pair) 검사가 포함되어 있다. 이 검 사는 난이도가 높아서 천장효과가 높은 기존의 CPT1의 단 점을 보완할 수 있고, 따라서 성인 주의력 평가에 사용되는 것으로 알려져 있다. ${ }^{26)}$ 본 연구결과 약물치료로 인해 누락오 류와 반응속도 표준편차의 감소가 관찰되었으며, 분할주의 력을 평가한 선행 외국 연구결과와 일치하는 소견이다. ${ }^{34)}$ 하 지만 분할주의력은 약물치료 전후로 차이가 없다는 보고도 있어 ${ }^{29,35)}$ 향후 보완적인 연구결과가 필요하다.

본 연구에서는 단순한 형태이기는 하나 실행주의력의 일부 를 평가할 수 있는 간섭주의력검사를 통해 약물 전후의 변화 를 조사하였다. 이 검사는 flanker 검사의 특성을 갖고 있어 서 간섭자극을 억제하면서 목표자극에 정확하고 빠르게 반 응하는 능력을 측정하는데, 이런 능력은 전두엽과 전측 대상 피질의 기능과 관련되어 있다. ${ }^{36,37)}$ 이 검사 역시 $\mathrm{MCD}$ 치료 후 에 누락 및 오경보오류, 반응속도 표준편차가 유의하게 감소 하였으며, 이는 약물치료 후 간섭을 억제하는 일부 전두엽 기 능이 향상되었음을 의미한다. 과거 연구에서는 간섭자극을 억제하는 능력이 $\mathrm{MPH}$ 치료 전후로 호전되었다는 결과 ${ }^{38,39)}$ 와 호전되지 않았다는 결과가 모두 보고되고 있다. ${ }^{31)}$

본 연구에서는 주의력 이외에도 작업기억력의 변화도 평가 하였다. 작업기억력 결손은 $\mathrm{ADHD}$ 의 핵심적인 신경심리적 특징으로서, 본 연구에서 평가한 시각적 작업기억력이 언어 적 작업기억력보다 $\mathrm{ADHD}$ 에서 더 중요하다고 알려져 있다. ${ }^{40)}$ 기존 연구를 살펴보면 $\mathrm{ADHD}$ 에서 $\mathrm{MPH}$ 치료 후에 공간 작 업기억력의 호전되었다는 결과 ${ }^{41,42}$ 와 약물이 작업기억력에 영 향을 전혀 미치는 못하였다는 결과 ${ }^{43}$ 가 모두 보고되었다. 본 연구결과에서도 전방향 기억폭만 유의하게 호전되었을 뿐, 다른 항목에는 유의한 차이가 관찰되지 않았다. 따라서 이 부 분에 대해서는 주의 깊은 해석이 필요하다.
본 연구결과 약 $40 \%$ 의 환자에서 한 가지 이상의 부작용이 발생하였다. 흔한 부작용으로 두통, 오심, 식욕저하, 복통, 불 면 등이 관찰되었다. 이는 외국의 $\mathrm{MCD}$ 연구결과를 검토한 결 과와도 거의 일치하는데, 외국에서도 가장 흔한 부작용으로 두통, 식욕저하, 복통, 불면이 보고되었다. ${ }^{22}$ 최근 들어 정신자 극제와 관련되어 큰 관심을 받고 있는 부작용은 성장 및 체중 과 관련된 것이다. ${ }^{44)}$ 비록 예비적이기는 하나 본 연구의 결과 를 통해 약물 투여 4주까지는 체중 감소가 관찰되다가 8주가 되면 약물치료 전과의 체중 차이가 사라지는 것을 관찰할 수 있었다. 이는 $\mathrm{ADHD}$ 아동의 신장과 체중을 10 년간 추적 조사 한 결과 정신자극제의 사용과 성장과는 연관성이 없었다는 최근 연구결과와 일맥상통하는 결과이다. ${ }^{45}$

본 연구는 비교군이 없는 개방형 연구이므로 인지기능평가 도구의 학습효과를 배제할 수 없으며, 약물의 실제 효과뿐 아 니라 효과에 대한 기대가 결과에 영향을 주었을 가능성이 있 다. 또한 본 연구대상군은 공존질환이 상대적으로 적게 포함 되어 있어서 본 연구의 결과를 공존질환을 갖고 있는 $\mathrm{ADHD}$ 환자에게 적용할 때에는 주의가 필요하다.

\section{결 론}

본 연구를 통해 국내 $\mathrm{ADHD}$ 아동 및 청소년에서 $\mathrm{MCD}$ 의 효능과 안전성을 처음으로 보고하였다. 포괄적인 신경인지기 능 검사를 통해 $\mathrm{MCD}$ 가 지속주의력과 경계력을 증가시키고 충동적인 반응을 감소시킬 수 있음을 관찰하였다. 뿐만 아니 라 반응의 일관성과 간섭 자극을 배제하는 능력을 증가시키 고, 두 가지 자극에도 주의력을 유지시키는 능력과 작업기억 력을 향상시킬 수 있음을 관찰하였다.

중심 단어:주의력결핍 과잉행동장애·메타데이트 CD·효능 · 안전성 · 종합주의력검사 도구.

\section{References}

1) Biederman J. Attention-deficit/hyperactivity disorder: a life-span perspective. J Clin Psychiatry 1998;59 Suppl 7:4-16.

2) Brams M, Moon E, Pucci M, López FA. Duration of effect of oral long-acting stimulant medications for ADHD throughout the day. Curr Med Res Opin 2010;26:1809-1825.

3) Adler LD, Nierenberg AA. Review of medication adherence in children and adults with ADHD. Postgrad Med 2010;122:184-191.

4) Birmaher B, Greenhill LL, Cooper TB, Fried J, Maminski B. Sustained release methylphenidate: pharmacokinetic studies in ADDH males. J Am Acad Child Adolesc Psychiatry 1989;28:768-772.

5) Pelham WE Jr, Sturges J, Hoza J, Schmidt C, Bijlsma JJ, Milich R, et al. Sustained release and standard methylphenidate effects on cognitive and social behavior in children with attention deficit disorder. Pediatrics 1987;80:491-501.

6) Greenhill LL, Findling RL, Swanson JM; ADHD Study Group. A 
double-blind, placebo-controlled study of modified-release methylphenidate in children with attention-deficit/hyperactivity disorder. Pediatrics 2002;109:E39.

7) Dirksen SJ, D'Imperio JM, Birdsall D, Hatch SJ. A postmarketing clinical experience study of Metadate CD. Curr Med Res Opin 2002; 18:371-380.

8) Pietrzak RH, Mollica CM, Maruff P, Snyder PJ. Cognitive effects of immediate-release methylphenidate in children with attentiondeficit/hyperactivity disorder. Neurosci Biobehav Rev 2006;30: 1225-1245.

9) Lee SH, Song DH, Kim BN, Joung YS, Ha EH, Cheon KA, et al. Variability of response time as a predictor of methylphenidate treatment response in korean children with attention deficit hyperactivity disorder. Yonsei Med J 2009;50:650-655.

10) Song DH, Shin DW, Jon DI, Ha EH. Effects of methylphenidate on quantitative EEG of boys with attention-deficit hyperactivity disorder in continuous performance test. Yonsei Med J 2005;46:34-41.

11) Han DH, Lee YS, Na C, Ahn JY, Chung US, Daniels MA, et al. The effect of methylphenidate on Internet video game play in children with attention-deficit/hyperactivity disorder. Compr Psychiatry 2009;50:251-256.

12) Kim Y, Shin MS, Kim JW, Yoo HJ, Cho SC, Kim BN. Neurocognitive effects of switching from methylphenidate-IR to OROS-methylphenidate in children with ADHD. Hum Psychopharmacol 2009; 24:95-102.

13) Lee SI, Hong SD, Kim SY, Kim EJ, Kim JH, Kim JH, et al. Efficacy and tolerability of OROS methylphenidate in Korean children with attention-deficit/hyperactivity disorder. Prog Neuropsychopharmacol Biol Psychiatry 2007;31:210-216.

14) Kim YS, Cheon KA, Kim BN, Chang SA, Yoo HJ, Kim JW, et al. The reliability and validity of Kiddie-Schedule for Affective Disorders and Schizophrenia-Present and Lifetime Version- Korean version (K-SADS-PL-K). Yonsei Med J 2004;45:81-89.

15) DuPaul GJ, Power TJ, Anastopoulos AD, Reid R. ADHD Rating Scale-IV: Checklists, Norms, and Clinical Interpretations. New York: The Guilford Press; 1998.

16) Conners CK, Barkley RA. Rating scales and checklists for child psychopharmacology. Psychopharmacol Bull 1985;21:809-843.

17) Guy W. ECDEU Assessment Manual for Psychopharmacology. Rockville: US Dept Health, Education, and Welfare publication;1976.

18) Yoo HK, Lee J, Kang SH, Park EH, Jung J, Kim BN, et al. Standardization of the comprehensive attention test for the Korean children and adolescents. J Korean Acad Child Adolesc Psychiatry 2009;20: 68-75.

19) Yoon HJ, Yook KH, Jon DI, Seok JH, Hong N, Cho SS, et al. Efficacy and tolerability of osmotic release oral system-methylphenidate in children with attention-deficit hyperactivity disorder according to comorbid psychiatric disorders. J Korean Acad Adolesc Psychiatry 2008;19:147-155.

20) Kim B, Park E. An observational multi-center study for evaluation of efficacy, safety and parental satisraction of methylphenidateOROS in children with ADHD. J Korean Acad Adolesc Psychiatry 2005;16:279-285.

21) Pliszka SR, Crismon ML, Hughes CW, Corners CK, Emslie GJ, Jensen PS, et al. The Texas Children's Medication Algorithm Project: revision of the algorithm for pharmacotherapy of attention-deficit/hyperactivity disorder. J Am Acad Child Adolesc Psychiatry 2006;45:642-657.

22) Anderson VR, Keating GM. Methylphenidate controlled-delivery capsules (EquasymXL, Metadate CD): a review of its use in the treatment of children and adolescents with attention-deficit hyperactivity disorder. Paediatr Drugs 2006;8:319-333.

23) Haessler F, Tracik F, Dietrich H, Stammer H, Klatt J. A pharmacokinetic study of two modified-release methylphenidate formulations under different food conditions in healthy volunteers. Int J Clin Pharmacol Ther 2008;46:466-476.
24) Swanson JM, Wigal SB, Wigal T, Sonuga-Barke E, Greenhill LL, Biederman J, et al. A comparison of once-daily extended-release methylphenidate formulations in children with attention-deficit/ hyperactivity disorder in the laboratory school (the Comacs Study). Pediatrics 2004;113:e206-e216.

25) Pentikis HS, Simmons RD, Benedict MF, Hatch SJ. Methylphenidate bioavailability in adults when an extended-release multiparticulate formulation is administered sprinkled on food or as an intact capsule. J Am Acad Child Adolesc Psychiatry 2002;41:443-449.

26) Riccio CA, Waldrop JJ, Reynolds CR, Lowe P. Effects of stimulants on the continuous performance test (CPT): implications for CPT use and interpretation. J Neuropsychiatry Clin Neurosci 2001;13:326335.

27) Nass RD. Evaluation and assessment issues in the diagnosis of attention deficit hyperactivity disorder. Semin Pediatr Neurol 2005; 12:200-216

28) Nigg JT. Neuropsychologic theory and findings in attention-deficit/ hyperactivity disorder: the state of the field and salient challenges for the coming decade. Biol Psychiatry 2005;57:1424-1435.

29) Konrad K, Gunther T, Hanisch C, Herpertz-Dahlmann B. Differential effects of methylphenidate on attentional functions in children with attention-deficit/hyperactivity disorder. J Am Acad Child Adolesc Psychiatry 2004;43:191-198.

30) Trommer BL, Hoeppner JA, Zecker SG. The go-no go test in attention deficit disorder is sensitive to methylphenidate. J Child Neurol 1991;6 Suppl:S128-S131.

31) Scheres A, Oosterlaan J, Swanson J, Morein-Zamir S, Meiran N, Schut H, et al. The effect of methylphenidate on three forms of response inhibition in boys with AD/HD. J Abnorm Child Psychol 2003;31:105-120.

32) Konrad K, Günther T, Heinzel-Gutenbrunner M, Herpertz-Dahlmann B. Clinical evaluation of subjective and objective changes in motor activity and attention in children with attention-deficit/hyperactivity disorder in a double-blind methylphenidate trial. J Child Adolesc Psychopharmacol 2005;15:180-190.

33) Bedard AC, Ickowicz A, Logan GD, Hogg-Johnson S, Schachar R, Tannock R. Selective inhibition in children with attention-deficit hyperactivity disorder off and on stimulant medication. J Abnorm Child Psychol 2003;31:315-127.

34) de Sonneville LM, Njiokiktjien C, Bos H. Methylphenidate and information processing. Part 1: Differentiation between responders and nonresponders; Part 2: Efficacy in responders. J Clin Exp Neuropsychol 1994;16:877-897.

35) Hanisch C, Konrad K, Günther T, Herpertz-Dahlmann B. Agedependent neuropsychological deficits and effects of methylphenidate in children with attention-deficit/hyperactivity disorder: a comparison of pre- and grade-school children. J Neural Transm 2004; 111:865-881.

36) Fan J, McCandliss BD, Sommer T, Raz A, Posner MI. Testing the efficiency and independence of attentional networks. J Cogn Neurosci 2002;14:340-347.

37) Raz A, Buhle J. Typologies of attentional networks. Nat Rev Neurosci 2006;7:367-379

38) Jonkman LM, Kemner C, Verbaten MN, Van Engeland H, Kenemans JL, Camfferman G, et al. Perceptual and response interference in children with attention-deficit hyperactivity disorder, and the effects of methylphenidate. Psychophysiology 1999;36:419-429.

39) Ridderinkhof KR, Scheres A, Oosterlaan J, Sergeant JA. Delta plots in the study of individual differences: new tools reveal response inhibition deficits in $\mathrm{AD} / \mathrm{Hd}$ that are eliminated by methylphenidate treatment. J Abnorm Psychol 2005;114:197-215.

40) Castellanos FX, Tannock R. Neuroscience of attention-deficit/hyperactivity disorder: the search for endophenotypes. Nat Rev Neurosci 2002;3:617-628.

41) Bedard AC, Martinussen R, Ickowicz A, Tannock R. Methylphenidate improves visual-spatial memory in children with attention- 
deficit/hyperactivity disorder. J Am Acad Child Adolesc Psychiatry 2004;43:260-268.

42) Mehta MA, Goodyer IM, Sahakian BJ. Methylphenidate improves working memory and set-shifting in $\mathrm{AD} / \mathrm{HD}$ : relationships to baseline memory capacity. J Child Psychol Psychiatry 2004;45:293-305.

43) Rhodes SM, Coghill DR, Matthews K. Methylphenidate restores visual memory, but not working memory function in attention deficit-hyperkinetic disorder. Psychopharmacology (Berl) 2004;175:319-
330.

44) Faraone SV, Biederman J, Morley CP, Spencer TJ. Effect of stimulants on height and weight: a review of the literature. J Am Acad Child Adolesc Psychiatry 2008;47:994-1009.

45) Biederman J, Spencer TJ, Monuteaux MC, Faraone SV. A naturalistic 10-year prospective study of height and weight in children with attention-deficit hyperactivity disorder grown up: sex and treatment effects. J Pediatr 2010;157:635-640, 640.e1. 